\title{
The Implementation and Discussion of the Experiential Rhythm Teaching Mode of College Public Music Courses
}

\author{
Ju Wang ${ }^{1, *}$, Shengjing $\mathrm{Wu}^{2}$ \\ ${ }^{1}$ College of Teacher Education, Leshan Normal University, Leshan, China \\ ${ }^{2}$ College of Fine Arts, Leshan Normal University, Leshan, China \\ *Corresponding author. Email: 396553654@qq.com
}

\begin{abstract}
With the development of subject teaching and the introduction of new music curriculum standards, The development and reform of music teaching in universities are also gradually advancing students' comprehensive quality. In the "aesthetic education, to beautify people" under the background of aesthetic education, it is an important idea for colleges and universities to cultivate all-round talents with comprehensive quality rhythm teaching of this course is the reform and attempt of public music course teaching. Based on the requirements of subject quality in the new music curriculum standards in 2017 edition, the design of the experience-first teaching method, the use of multiple experience, multi-ways to perceive the way of music, 3D rendering present music content. On the basis of stimulating learning interest and cultivating innovation ability, the comprehensive quality of subjects should be improved.
\end{abstract}

Keywords: The rhythm of experience, Music perception, Aesthetics education.

\section{BACKGROUND}

From the implementation of the first edition of the new curriculum standard in 2001 to the new curriculum standards of high school music based on core literacy were introduced and implemented in 2017, our music teaching has been going further and further on the road of reform, and the study of music is also closer to the music itself and the cultivation of learners' musical perception, listening ability and expressive force, focusing on the cultivation of musical aesthetic ability in the perception of music. In normal colleges and universities in China, in content, the teaching of public music courses is mainly based on music appreciation, and in teaching methods, mainly on teaching knowledge and music appreciation, so students lack the necessary perception in personal experience. In music classroom teaching, the feedback out of the question is: The teaching method is relatively single, the experience feeling in music learning is not rich enough, and for the emotional experience, the external feeling is more than the students' personal experience. Music is a subject that relies on hearing to learn, distinguishing music and sound is must be repeatedly led and repeatedly experienced in the music classroom teaching. That students learn and master the content of music knowledge level is only the lowest level of music learning requirements, which means students can't really feel the clever change of music in the aesthetic sense and the resulting psychological feelings and experience. The lack of experience of the music class, causes that students can't deeply feel the charm of music art, also causes that the music aesthetic discrimination of students is vague and not clear. Based on this, the public music course should start with aesthetic experience, strengthen students' multiple music experience, let students feel and comprehend the beauty of music in music practice, learn music knowledge in the process of feeling and experiencing, and then make music expression in line with the discipline requirements and music aesthetic.

Although there are many ways for students to accept music in life and study, it's hard to advance the art education of musical study. This paper's teaching reform measures is on the basis of the teaching of common courses in the music, combining with teaching ideas and methods of the internationally famous Orff music, giving priority to music rhythm feeling and experience appreciation on the subject training, proceeding with the practicality and practicality of music, emphasizing the experiences on how to enhance the students' emotional experience, enriching classroom teaching at the same time, mobilizing students' learning enthusiasm and creativity greatly. Examples of lessons created are paying attention to the development of the students' innovative ability, exercises of music improvisational ability and practices of body coordination ability, making the music classroom teaching different from the conventional music classroom teaching, which is multi-angle emphasised and multi-channel experienced, especially achieved some results for the lead and comprehension at the 
music appreciation level. The effect has already won appreciation from teachers and students widely.

\section{THE MEASURES AND METHODS OF CURRICULUM REFORM}

\subsection{Establish the Teaching Mode of Dynamic Rhythm}

The curriculum reform focuses on the improvement of degree of students' active participation and personal experience, so as to help students gradually rebuild their cognitive structure in music and make corresponding changes in the process of learning. So rhythm teaching is chosen as the main teaching mode in the reform of music public course: with rhythm as the guide, it integrates language, body movements, non-musical instruments and so on, in the way of movement, and integrates life, fun and music, while rhythm teaching is designed to strengthen students' experience of rhythm. Through the dynamic experience mode, the design takes action as the first step, so that students can be exposed to a good music learning environment, and it will be integrated with the music itself to achieve the multi-sensory experience of vision, hearing, touch and so on, and obtain a good sense of rhythm.

\subsection{Gamification of Rhythm Teaching}

As a natural phenomenon of human growth, games are easier to be understood and accepted by students. Trying to integrate games into classroom teaching design often leads to better teaching results than conventional teaching methods. Given this, rhythm teaching in the public music elective course uses the forms of dance movements and finger ballads to design the play-based rhythm teaching, so as to stimulate students' interest in learning and encourage them to actively participate in music teaching activities.

\subsubsection{Game Teaching with Action Participation}

The teaching of the game is based on rhythmic movements and orchestic movements. Through the selection of music with distinct rhythm, regular segments, smooth melody and easy singing, certain dance movements and rhythmic movements are set, and, corresponding music, certain dance formation is designed, such as a circle, etc. In the circle, students make collective actions in clockwise or counter clockwise direction. The purpose of this playful action is to lead students into the music in a playful way under the premise of action participation, and to listen and learn music beats, rhythm and other elements imperceptibly with action as dominant guidance. Its advantage is that students' musical learning is conducted in inadvertently, and it can weaken the traditional music teaching of pure knowledge in the teaching process, lead which into the classroom teaching integrated of action, musicality and gameplay, so the ascension of knowledge learning, music feeling and music accomplishment becomes more natural, eventually the teaching aim of music learning is achieved in seemingly unconscious game activities.

\subsubsection{Finger Involvement in the Game Teaching}

Finger dexterity training is very important in music learning, especially in learning of instruments. However, it is difficult to carry out the professional finger training similar to musical instrumental learning. But it is easy to carry out rhythmic training with the aid of finger language, and enhance students' interest.

This teaching attempts to introduce finger ballads into public music classroom teaching. Through the participation of fingers, the teaching of rhythm is completed, so as to cultivate students' sense of rhythm, and at the same time exercise the local movement ability of hand-eye coordination, fingertip movement and finger stretching. It also can promote learners' coordination between hand and brain as well as the coordination among hand and various senses, and also provide a foundation for musical instrument learning.

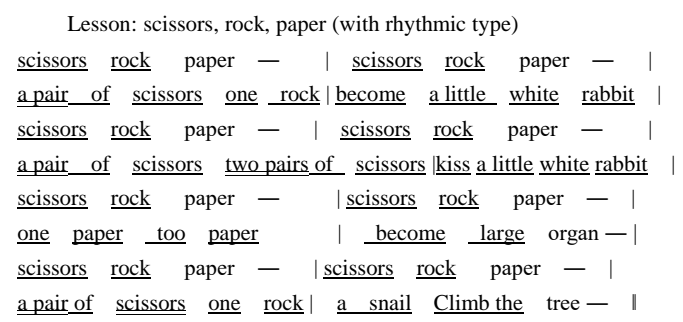

This lesson example is based on the rhythm game of finger rhymes created by children's rhymes. The shape of scissors, rock and paper made by hand is very familiar to everyone, so it can stimulate students' interest in learning. The teaching form is more flexible, can be carried out according to the rhythm of the class example, and students themselves can design the rhythm of scissors, rock, paper and create a new animal or object image, and choose the appropriate music, etc. The principle of instructional design is that it is easier for learners to accept familiar things which can shorten the time for students to accept unknown learning contents. The participation of games can improve the learning interest and render the classroom atmosphere. It realize the memory of rhythm pattern, and apply it to a variety of music learning, such as song learning, music listening and appreciation, instrumental music learning and so on.

\subsection{Physical Involvement in Rhythm Teaching}

In music rhythm teaching, we can try to learn and experience by beating various parts of the body. Rhythm teaching with physical participation mainly focuses on 
body movements such as clapping hands and stomping feet. After students master the above movements, they gradually increase the beating of body parts according to the content of the music, which expands the scope of sound exploration and increases students' multi-dimensional and multi-angle experience of the sound. The participation of body movements finally presents a rich, varied and lively body percussion form. Also, collaborative body percussion experiences can be designed. Flaping different parts of the body will achieve the body perception of rhythm, and achieve the flow of rhythm through the cooperation of each other.

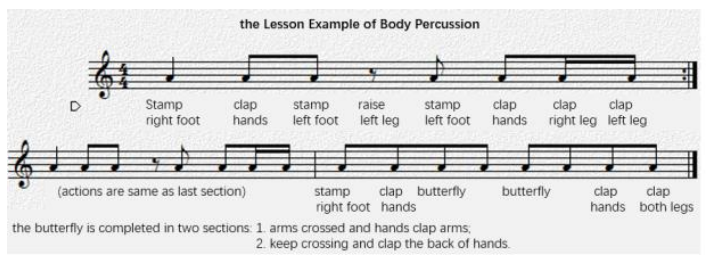

Figure 1 The lesion Example of Body percussion.

\subsection{Rhythm of Common Living Objects Involved}

The participation of common objects in life in music teaching is based on students' life experience to conduct creative music teaching, inspire their creative thinking.

\subsubsection{Rhythm of the Table}

The rhythmic teaching design of the table is the comprehensive design combining the hands, arms, elbows and other parts, its movements are palm beat, fist hammer, elbow and arm knock, and so on. Rhythm teaching combining table and body parts pays attention to the sound generated by the striking between different body parts and the table top, so the richer the movement is, the more hierarchical the sound is. Students' music experience is more real and natural, and their cognition of rhythm learning is also more profound and unforgettable. Rhythm experience combining hand movements and desk helps students better grasp the rhythm and understand the dynamic and diversity of rhythm teaching methods.

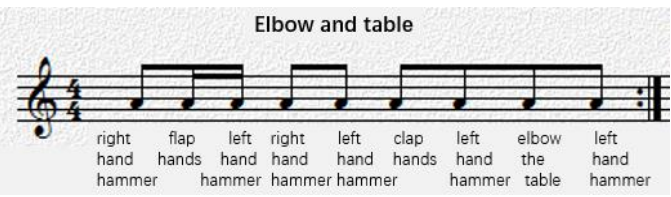

Figure 2 Elbow and table.

\subsubsection{Rhythm of the Cup}

Cups make different sounds when they are knocked or bumped because of different materials. As a result, as the object of sound exploration in music class, the cup naturally has its unique timbre and usage. Fully considering its characteristics in the teaching, the cup is designed as props of sound to explore, through the taking and putting of the cup, combining with clapping movements and the knock between cup and table or ground to realize different transformation of the sound. In the dynamic display of the cup, richness of rhythm teaching is experienced and felt, and the emergence of dynamic and orchestic rhythm is formed, so students can hold rhythms in the process of playing. Enriching the rhythm teaching methods and sound experience makes the rhythm learning more vivid and rich. The participation of cups also plays the effect of musical instrument accompaniment, it not only stimulates students' interest in learning, but also helps students better understand and master the rhythm pattern.

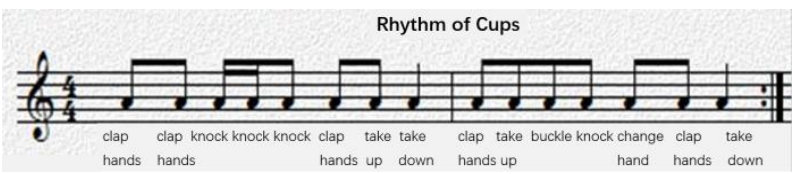

Figure 3 Rhythm of Cups.

\subsubsection{Rhythm of the Stool}

The stool is used like a table. Compared with the bulkiness of table, the practice participated with stool in the rhythm is more light and flexible in operation, and the design of the movements is also more rich. In addition to the commonly used flapping, the stool can also be designed to "throw, turn, catch" and other movements to carry out rhythm teaching. The students experience rhythm teaching with stool participation can develop students' rhythm cognition.

\section{PROBLEMS DISCUSSED}

The purpose of setting up public music courses in normal colleges and universities is to let students feel the beauty of music art first, so as to achieve the purpose of aesthetic education. The reform practice of rhythm teaching of the music public course, let more students accepted the unconventional music teaching experience, improve their cognition to the rhythm of music and their aesthetic cognition on the level of music appreciation, clarify that the music rhythm is not only similar to the combination of mathematical formula, but is the technique of process and development of music. For students, it is necessary and critical to change their cognition of music rhythm teaching. In rhythm teaching, students receive new rhythm teaching training through multiple ways of rhythm experience, and at the same time, they can create rhythm experience of their own understanding in the rhythm experience.

This course has made classroom teaching reform in line with the requirements of music class standards and aesthetic education, also achieved some results. However, in order to comprehensively improve the 
music art aesthetic ability of normal students, strengthen the role of curriculum in aesthetic education and the reflection of college music curriculum in the inheritance of traditional music culture, it is far from enough now. At present, the problems need to be discussed include:

\subsection{The Change of Music Teaching Idea and Teachers}

The problem of teaching concept is relatively easy to change in theory, but the practicality of music teaching requires strong music innovative ability and creativity, so as to realize the innovative teaching of music subject, and realize more classroom teaching focusing on music experience and music feeling. Therefore, in the process of teaching implementation, teachers' ideas should not only be combined with the current music class standard, but also need to be related to students' actuality and classroom teaching. Teachers should not only have certain music professional skills, but also have the ability to research and create the curriculum system. Meanwhile, they should also reform the music classroom according to the actual situation of students, reform music classes together, in order to achieve satisfactory music learning effect and better music aesthetic experience. Therefore, higher requirements are put forward for teachers engaged in public music teaching.

\subsection{Cultivation of Interest in Music Learning}

Because of the curriculum setting or classroom teaching, in the actual teaching, there often appear problem that students like music, but do not like the music class. In course teaching, the improvement of music aesthetics can only be achieved by the participation of both teachers and students, especially for the recipients. Music learning and aesthetic experience can only be realized through a multi-way comprehensive experience. For example, students like pop music but they are not reluctant to learn and listen to folk music. The main reason is that popular music is contemporary and shocking, while most folk music is reserved and implicit, which requires more cognition to appreciate its beauty, so this situation also puts forward higher requirements for teachers' teaching in music class. Although the public course of music has solved some problems by means of elective credits and curriculum setting, it is more effective to let most students take the initiative to accept it from the perspective of interest, which is also the need for in-depth discussion in the future.

\subsection{Extracurricular Practice Extension of Music Classroom Teaching}

The main purpose of the reform of music classroom teaching is to help students feel the beauty of music more, so as the extension of classroom teaching, organizing multi-way and multi-form performance practice is an effective method. At present, in view of the reform of rhythm teaching of this course, students' performance practice participation is also a performance dominated by practical teaching participation. Although in the popularization of music and aesthetic education, the curriculum reform has done a variety of forms of teaching reform and methods of attempt, and also played a certain good teaching effect, in view of the current situation, the educational and teaching approaches developed by the practical reform and practice of the university music public course are far from meeting the needs of the current aesthetic education. We hope to find more effective modes and methods of music classroom teaching in the future exchanges and cooperation with similar colleges, the same major or similar majors.

\section{CONCLUSION}

The core quality of music consists of three connotations, which are aesthetic perception, artistic expression and cultural understanding. The attempt and implementation of experiential rhythm teaching is based on musical rhythm, creatively proceeding musical aesthetic perception, understanding and mastering musical elements and realizing means of musical expression in the process of experiencing and perceiving music. In the music perception generated dynamically, students gradually approach and understand the culture contained in the music itself, so as to improve their own literacy of music.

\section{ACKNOWLEDGMENT}

This is one research result of the Leshan Normal University's 2018 education and teaching reform research project, the exploration of critical thinking in the teaching module of music appreciation in primary and secondary schools.( Serial number: JG2018-1-ZF-1)

It is also one of the results of the 2019 study on the first-class and top-quality course of music education at Leshan Normal University, the course construction and the training model of music teaching skills for normal school students. (Serial number: KG2019-1-36)

\section{REFERENCES}

[1] Ju Wang. Orientation and Implementation Measures of Innovative Music Teaching Model in Middle School-An Empirical Study on Rhythm Teaching $[\mathrm{J}]$. Photocopying materials of newspapers and periodicals of Renmin University of China<Middle School Politics and Other Science, Education and Learning>. 2017.8.

[2] Yong shi. Music Theory and Culture [M]. Southwest Normal University Press, 2012.6. 